\title{
Vocabulary Subtest (WAIS-IV)
}

National Cancer Institute

\section{Source}

National Cancer Institute. Vocabulary Subtest (WAIS-IV). NCI Thesaurus. Code C120367.

Wechsler Adult Intelligence Scale, 4th Edition. The subject either names objects

presented visually or defines words that are presented visually and orally. 